\title{
BMJ The epidemiology of malpractice claims Open in primary care: a systematic review
}

\author{
E Wallace, ${ }^{1} \mathrm{~J}$ Lowry, ${ }^{2} \mathrm{~S}$ M Smith, ${ }^{1}$ T Fahey ${ }^{1}$
}

To cite: Wallace E, Lowry J, Smith SM, et al. The epidemiology of malpractice claims in primary care: a systematic review. BMJ Open 2013;3:e002929.

doi:10.1136/bmjopen-2013002929

- Prepublication history and additional material for this paper is available online. To view these files please visit the journal online (http://dx.doi.org/10.1136/ bmjopen-2013-002929).

Received 22 March 2013 Accepted 17 May 2013

This final article is available for use under the terms of the Creative Commons Attribution Non-Commercial 2.0 Licence; see http://bmjopen.bmj.com

\footnotetext{
${ }^{1}$ HRB Centre for Primary Care Research, Royal College of Surgeons in Ireland Medical School, Dublin, Ireland ${ }^{2}$ Department of Medicine, Trinity College Dublin, Dublin, Ireland
}

\section{Correspondence to} Dr Emma Wallace; emmawallace@rcsi.ie

\section{ABSTRACT}

Objectives: The aim of this systematic review was to examine the epidemiology of malpractice claims in primary care.

Design: A computerised systematic literature search was conducted. Studies were included if they reported original data ( $\geq 10$ cases) pertinent to malpractice claims, were based in primary care and were published in the English language. Data were synthesised using a narrative approach.

Setting: Primary care.

Participants: Malpractice claimants.

Primary outcome: Malpractice claim (defined as a written demand for compensation for medical injury). We recorded: medical misadventure cited in claims, missed/delayed diagnoses cited in claims, outcome of claims, prevalence of claims and compensation awarded to claimants.

Results: Of the 7152 articles retrieved by electronic search, a total of 34 studies met the inclusion criteria and were included in the narrative analysis.

Twenty-eight studies presented data from medical indemnity malpractice claims databases and six studies presented survey data. Fifteen studies were based in the USA, nine in the UK, seven in Australia, one in Canada and two in France. The commonest medical misadventure resulting in claims was failure to or delay in diagnosis, which represented $26-63 \%$ of all claims across included studies. Common missed or delayed diagnoses included cancer and myocardial infarction in adults and meningitis in children. Medication error represented the second commonest domain representing $5.6-20 \%$ of all claims across included studies. The prevalence of malpractice claims in primary care varied across countries. In the USA and Australia when compared with other clinical disciplines, general practice ranked in the top five specialties accounting for the most claims, representing 7.6-20\% of all claims. However, the majority of claims were successfully defended.

Conclusions: This review of malpractice claims in primary care highlights diagnosis and medication error as areas to be prioritised in developing educational strategies and risk management systems.

\section{INTRODUCTION}

Healthcare in the primary care setting is becoming increasingly complex. These

\section{ARTICLE SUMMARY}

Article focus

- Malpractice risk in primary care is understudied.

- An awareness of the epidemiology of malpractice claims in primary care could help inform risk management and educational strategies.

Key messages

- Failure to or delay in diagnosis was the commonest misadventure cited in malpractice claims.

- The diagnoses most frequently cited in claims for adults were cancer and myocardial infarction and for children, meningitis.

- Medication error was the second commonest reason for claims in primary care.

Strengths and limitations of the study

- Timely systematic review considering the increased focus on adverse events in primary care.

- Difficult to generalise findings considering the variation in the definition of primary care across countries and differences in clinical and legal systems.

- Limited to publications in English only.

complexities include caring for patients with multimorbidity and polypharmacy, the pressure of short consultation times and the increasingly fragmented nature of primary and secondary care. All these issues increase the risk of unintentional patient harm. ${ }^{1}$

Adverse events in the ambulatory setting are estimated at between 5 and 80 errors/ 100000 visits. $^{2}$ Attempts to classify medical errors and preventable adverse events in primary care have proved challenging due to the lack of an evidence base. ${ }^{3}{ }^{4}$ Classification measures include patient chart reviews, administrative database analysis, error reporting systems and malpractice claims reviews, none of which are without their limitations. ${ }^{5}$ The use of malpractice claims as a proxy for adverse events may be unrepresentative as the majority of adverse events will not result in a malpractice claim, and not all malpractice claims are brought as a result of medical 
negligence. ${ }^{6} 7$ Furthermore, malpractice claims represent a complex interplay of patient, doctor and societal factors, and therefore it is difficult to generalise findings due to variations in medical and legal systems and societal norms across countries. ${ }^{8}$ However, malpractice claims can offer insights into the types and causes of adverse events and have been used by clinical disciplines, such as anaesthetics, surgery and paediatrics, to determine 'higher risk' domains of practice. ${ }^{9-11}$ Malpractice claims in primary care remain relatively understudied despite their potential in informing relevant risk management systems for this setting. ${ }^{12} 13$

The aim of this systematic review was to examine the epidemiology of malpractice claims in primary care.

\section{METHODS}

\section{Search strategy}

The PRISMA guidelines for the reporting and conduct of systematic reviews were followed to conduct this review. ${ }^{14}$ A computerised literature search was conducted in April 2012 and updated in January 2013 using the following search engines: PubMed, EMBASE, CINAHL, Cochrane library, Google scholar, Scirus and legal databases (Heinonline, Justis, Lexisnexis and Westlaw). The search strategy details are provided in detail in online supplementary appendix 1 .

\section{Study selection and data extraction}

Studies were included if they met the following criteria:

1. Study type: studies presenting original data $(\geq 10$ cases) on malpractice claims.

2. Study setting: primary care, defined as: integrated, easy to access healthcare services by clinicians who are accountable for addressing a large majority of personal healthcare needs, developing a sustained and continuous relationship with patients, and practicing in the context of family and community. ${ }^{15}$

Studies relating to complaints that did not result in a malpractice claim were excluded. Studies focusing on outpatient or paediatric malpractice claims were included only if data specific to primary care were reported.

3. Outcome: malpractice claim; defined as a written demand for compensation for medical injury.

4. Published in the English language.

Two reviewers (EW and JL) read the titles and/or abstracts of the records and eliminated irrelevant studies. Studies that were considered eligible for inclusion were read fully in duplicate and their suitability for inclusion in the study was independently determined by both reviewers. Disagreements were managed by consensus. Additional data were sought from authors and medical indemnity organisations where necessary.

Data were extracted on each of the following: (1) study setting, (2) population studied, (3) type of data (eg, medical indemnity database, survey, etc), (4) prevalence of malpractice claims, (5) medical misadventure cited in claims, (6) types of missed/delayed diagnoses, (7) claims outcomes and (8) compensation awarded to claimants.

\section{Data synthesis}

A narrative synthesis of included studies was planned. A narrative review is discursive in nature and seeks to summarise the current state of knowledge in relation to a particular domain by considering a wide variety of sources and reaching conclusions through reason or argument. ${ }^{16}$

\section{RESULTS}

Study identification

A flow diagram of the search strategy is presented in figure 1. This yielded 7152 articles of which 6880 were excluded based on their title and/or abstract. The remaining 307 articles were assessed in full text. A total of 34 studies met the inclusion criteria and were included in the narrative analysis.

\section{Description of included studies}

Of a total of 34 included studies, 28 presented data from retrospective reviews of medical liability insurance databases ranging in terms of numbers included from 20 to 49345 malpractice claims (see online supplementary table S1). The remaining six studies presented survey data (see table 1). Fifteen studies were based in the USA, nine in the UK, seven in Australia, one in Canada and two in France. A description of the included named malpractice claims databases is presented in table 2 .

\section{EPIDEMIOLOGY OF MALPRACTICE CLAIMS IN PRIMARY CARE \\ Prevalence of malpractice claims}

A total of 19 studies reported either (1) malpractice claim prevalence rates or (2) the proportion of primary care claims as a percentage of all specialty claims on medical indemnity databases during specified time periods. Of these studies, 11 were based in the USA, four in Australia, three in the UK and one in France.

A US study of 4975 family practitioners which compared two study periods (1991-1995 and 2001-2003) reported that lower risk specialties in the USA, including family practice, saw a reduction in malpractice claims from $8.3 \%$ to $5.8 \%{ }^{17}$ The annual prevalence rate for family practitioner claims was $5.2 \%$. The estimated projected career cumulative risk of a malpractice claim was $76 \%$ by the age of 65 years. However, only $31 \%$ of these claims would be expected to result in compensation being awarded. ${ }^{17}$ A smaller study $(n=446)$ which focused on primary care claims (1997-2007) reported a paid malpractice claims prevalence rate of $8.7 \%{ }^{18}$

A US survey conducted in 1983 reported an annual prevalence rate of malpractice claims against family practitioners of $8.2 \% .^{19}$ When this survey was repeated in 1991 , this rate had fallen to $5.7 \% .{ }^{20}$ Other surveys in the 
Figure 1 PRISMA flow diagram of search strategy.

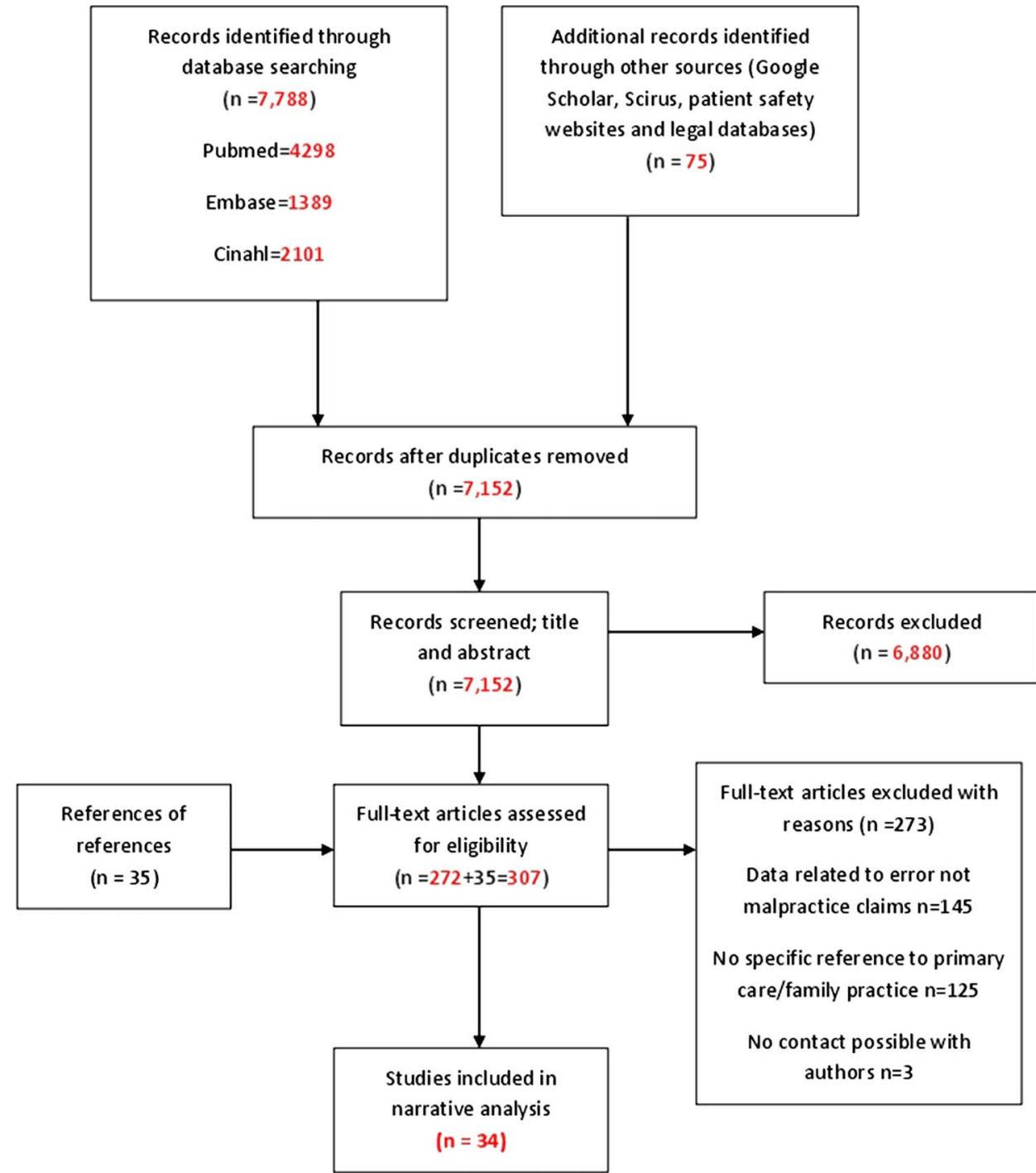

UK, Australia and the USA examining total career litigation reported rates of $12 \%, 21 \%$ and $38.9 \%$, respectively. $^{21-23}$ With regard to paediatric malpractice claims against general practitioners (GPs), a French review which reviewed 228 paediatric claims reported an annual prevalence rate of $0.07 \% .^{24}$

\section{Malpractice claims for primary care compared with other specialties}

Several studies presented the proportion of primary care malpractice claims compared with that of other specialties on medical indemnity databases. For instance, in a US review of 239756 closed malpractice claims for 28 specialties during the period 1985-2008, family practitioners ranked third overall, representing $11.5 \%$ of all claims. ${ }^{25}$ In another US review ( $n=1452$ claims), primary care ranked third of the nine specialties studied, representing $16 \%$ of the total claims reviewed. ${ }^{26}$ Five other studies reported proportions which ranged from $7.6 \%$ to $16 \%$ of total claims. ${ }^{27-31}$ In the UK, GPs represented the greatest proportion of an overall $20 \%$ increase in claims from 2009 to 2010 and claims involving GPs more than doubled in the period 1994-1999. ${ }^{32} 33$ In Australia, GPs had the highest proportion of malpractice claims and the highest number of new claims on the national Medical Indemnity National Collection database for the years 2009 and $2010 .^{34}$

\section{Medical misadventures cited in malpractice claims}

The medical misadventure most frequently cited related to failure to or delay in diagnosis, which accounted for 26-63\% of all malpractice claims across included studies. $^{25}$ 32-37 The most commonly recorded patient outcome was death, which ranged between $15 \%$ and $48 \%$ of all outcomes recorded in malpractice claims. $^{26} \quad 34 \quad 35 \quad 37-39$ One study found that failure in judgement, vigilance or memory and knowledge deficit were the most frequent factors involved. It also highlighted the important multifactorial nature of error. For instance, in $43 \%$ of errors studied, two or more clinicians contributed to the missed diagnosis while in $16 \%$, three or more contributed. ${ }^{35}$ A detailed analysis of delayed or missed diagnosis claims identified failure to order a diagnostic test, create a proper follow-up plan, 
Table 1 Studies reporting survey data relevant to primary care malpractice claims

\begin{tabular}{|c|c|c|c|c|c|}
\hline Author (year) & Setting & Data source & $\begin{array}{l}\text { Population } \\
\text { studied }\end{array}$ & Outcome & Findings \\
\hline \multirow[t]{2}{*}{ MPS (2011) } & UK & Survey of GP members & $\begin{array}{l}1 \text { in } 5 \text { related to } \\
\text { prescribing } \\
\text { related adverse } \\
\text { events }\end{array}$ & $\begin{array}{l}\text { Types of prescribing } \\
\text { errors }\end{array}$ & $\begin{array}{l}\text { Failure to warn of or } \\
\text { recognise side effects, right } \\
\text { drug-wrongly prescribed, } \\
\text { wrong drug prescribed, } \\
\text { injection related, drug } \\
\text { interaction or contraindicated }\end{array}$ \\
\hline & & & & $\begin{array}{l}\text { Frequently } \\
\text { implicated } \\
\text { medications }\end{array}$ & $\begin{array}{l}\text { Commonest medication } \\
\text { classes: steroids (oral and } \\
\text { topical), antibiotics (previous } \\
\text { known penicillin allergy or } \\
\text { sulphonamides), } \\
\text { phenothiazides, HRT, } \\
\text { COCP, narcotics, lithium and } \\
\text { anticoagulants (inadequate } \\
\text { monitoring) and NSAIDs }\end{array}$ \\
\hline MPS (2011) & UK & Survey & $\begin{array}{l}\mathrm{N}=670, \text { UK } \\
\text { MPS members }\end{array}$ & $\begin{array}{l}\text { Prevalence of } \\
\text { malpractice claims }\end{array}$ & $\begin{array}{l}27 \% \text { of respondents were } \\
\text { GPs of whom } 12 \% \text { had } \\
\text { experienced a malpractice } \\
\text { claim }\end{array}$ \\
\hline $\begin{array}{l}\text { American } \\
\text { Medical } \\
\text { Association } \\
\text { (AMA) (2010) }\end{array}$ & US & $\begin{array}{l}\text { Survey. Random } \\
\text { sampling of the AMA } \\
\text { repository, nationally } \\
\text { representative, 2007- } \\
2008\end{array}$ & $\begin{array}{l}\mathrm{N}=5285 \\
\text { physicians total } \\
\mathrm{N}=100 \mathrm{GPs} / \\
\text { Family } \\
\text { practitioners }\end{array}$ & $\begin{array}{l}\text { Prevalence of } \\
\text { malpractice claims }\end{array}$ & $\begin{array}{l}3.1 \% \text { sued in the previous } \\
\text { year } \\
38.9 \% \text { sued once in their } \\
\text { career } \\
22.2 \% \text { Sued more than once } \\
\text { in their career }\end{array}$ \\
\hline Nash (2009) & Australia & $\begin{array}{l}\text { Survey of doctors who } \\
\text { had been insured with } \\
\text { UNITED Medical } \\
\text { Protection }\end{array}$ & $\begin{array}{l}\mathrm{N}=582 \mathrm{GP} \\
\text { cohort } \\
33 \% \text { response } \\
\text { rate }\end{array}$ & $\begin{array}{l}\text { Prevalence of } \\
\text { malpractice claims } \\
\text { (Medico-legal matter } \\
\text { defined as a claim } \\
\text { for compensation or } \\
\text { complaint) }\end{array}$ & $\begin{array}{l}\text { Of GP cohort; } \\
\text { Currently involved in } \\
\text { medicolegal matter-9\% } \\
\text { Ever involved in medicolegal } \\
\text { matter-58\% } \\
\text { Claim for compensation } \\
\text { related to malpractice- } 21 \%\end{array}$ \\
\hline AMA (1993) & US & Survey & & $\begin{array}{l}\text { Prevalence of } \\
\text { malpractice claims }\end{array}$ & $\begin{array}{l}\text { For GPs, the rate was } 5.7 \\
\text { per } 100 \text { in } 1991\end{array}$ \\
\hline $\begin{array}{l}\text { Zuckerman } \\
\text { (1984) }\end{array}$ & US & $\begin{array}{l}\text { Survey of the AMA } \\
\text { Socioeconomic } \\
\text { Monitoring System } \\
(1978-1983)\end{array}$ & $\begin{array}{l}\mathrm{N}=1240, \text { All } \\
\text { specialties }\end{array}$ & $\begin{array}{l}\text { Prevalence of } \\
\text { malpractice claims } \\
\text { per specialty }\end{array}$ & $\begin{array}{l}\text { For general/family practice, } \\
\text { annual claims rate } 8.7 \% \\
\text { (1978-1983), prior to } 1978 \text {, } \\
3.8 \%\end{array}$ \\
\hline
\end{tabular}

adequately obtain a history or perform a physical examination and incorrect interpretation of a diagnostic test result as the commonest processes involved. ${ }^{35}$

In adults, the commonest missed or delayed diagnoses recorded were largely consistent across studies, namely (1) cancer (most commonly breast, colon, melanoma, lung and female genital tract) and (2) circulatory system (most commonly myocardial infarction). Other frequently cited missed or delayed diagnoses included appendicitis, ectopic pregnancy and fractures. ${ }^{33} 363840$ In children, two studies reported meningitis, gastroenteritis, pneumonia, appendicitis, sepsis and malignancy as the commonest conditions resulting in claims. $^{24} 29$ According to the child's age, dehydration, meningitis and congenital dislocation of the hip were commonest for those $<2$ years, pneumonia, malignancy and appendicitis for those aged 3-11 years, and trauma, testicular torsion and malignancy for older children (12-18 years).$^{24}$ In a UK review of paediatric meningitis and septicaemia claims $(n=20$, reported between 2001 and 2011), both individual and systems emerged as contributing factors. ${ }^{41}$ Individual factors included poor documentation and management deficiencies such as inadequate safety-netting. Systems errors included inadequate practice cross-communication and poor provision for emergencies in appointment systems. While a missed or delayed diagnosis of meningitis accounted for only $1 \%$ of all claims, it accounted for $30 \%$ of total settlement costs. ${ }^{40}$

Overall, the second commonest medical misadventure cited in malpractice claims was medication error ranging from $5.6 \%$ to $20 \%$ across included studies. ${ }^{33} \quad 374243$ 
Table 2 Description of included named medical indemnity databases

\begin{tabular}{|c|c|c|}
\hline Name of database & Setting & Description of database \\
\hline $\begin{array}{l}\text { Data sharing project of the } \\
\text { Physician Insurers } \\
\text { Association of America } \\
\text { (PIAA) }\end{array}$ & USA & $\begin{array}{l}\text { Trade association of }>50 \text { medical malpractice insurance companies which insure } \\
\text { approximately } 60 \% \text { of all privately practicing physicians in the USA. In } 1985 \text {, the } \\
\text { Data Sharing Project was established which pools data for approximately } 22 \\
\text { member companies representing approximately } 25 \% \text { of the medical malpractice } \\
\text { claims at a specific time point. It provides specialty-specific information }\end{array}$ \\
\hline $\begin{array}{l}\text { Controlled Risk Insurance } \\
\text { Companies (CRICOs) }\end{array}$ & USA & $\begin{array}{l}\text { Comprises three companies owned by and serving the Harvard medical } \\
\text { communities; the Controlled Risk Insurance Company of Vermont, Inc, the } \\
\text { Controlled Risk Insurance Company, Ltd. and the Risk Management Foundation } \\
\text { (RMF). Together, these companies insure approximately } 83000 \text { physicians in } \\
\text { Massachusetts and New Hampshire }\end{array}$ \\
\hline The Doctors' Company & USA & Physician-owned medical liability insurer which insures $>73000$ doctors in the USA \\
\hline $\begin{array}{l}\text { Medical Defence Union } \\
\text { (MDU) }\end{array}$ & UK & $\begin{array}{l}\text { Medical defence organisation and a mutual company owned by its members, with } \\
>200000 \text { members in the UK and Ireland }\end{array}$ \\
\hline $\begin{array}{l}\text { Medical Protection Society } \\
\text { (MPS) }\end{array}$ & UK & $\begin{array}{l}\text { Medical defence organisation and a mutual company with }>270000 \text { members } \\
\text { internationally. The main jurisdictions are the UK and Ireland but also include South } \\
\text { Africa, New Zealand, Hong Kong, Singapore, Malaysia, the Caribbean, Bermuda } \\
\text { and Kenya. It includes both open and closed malpractice claims }\end{array}$ \\
\hline $\begin{array}{l}\text { Medical Indemnity National } \\
\text { Collection (MINC) }\end{array}$ & Australia & $\begin{array}{l}\text { Database for medical malpractice claims for the public and private sectors in } \\
\text { Australia. There is mandatory reporting of claims to the MINC by all medical } \\
\text { indemnity insurers since } 2003 \text {, so this database should have } 100 \% \text { coverage. It } \\
\text { includes open and closed malpractice claims. Of note, more than one claim may be } \\
\text { opened for the same incident, for example, if the GP has insurance with more than } \\
\text { one medical indemnifier or if multiple clinicians are involved in the same claim. } \\
\text { Therefore, one claim may be counted more than once }\end{array}$ \\
\hline $\begin{array}{l}\text { Sou Medical-Groupe } \\
\text { MACSF insurance } \\
\text { company }\end{array}$ & France & $\begin{array}{l}\text { Database for medical malpractice claims inputted from a nationwide medical } \\
\text { insurance company covering } 45000 \text { GPs in France. It corresponds to approximately } \\
60 \% \text { of physicians working in France and includes all malpractice claims reported to } \\
\text { the region's government-appointed review board regardless of outcome }\end{array}$ \\
\hline $\begin{array}{l}\text { Canadian Medical } \\
\text { Protective Association } \\
\text { (CMPA) }\end{array}$ & Canada & $\begin{array}{l}\text { Physician-owned medical defence union whose membership comprises most } \\
\text { practising physicians in Canada and serves over } 83000 \text { members }\end{array}$ \\
\hline
\end{tabular}

A recent UK review reported that prescribing error, inappropriate medication, drug administration errors, dispensing errors and adverse drug reactions are the commonest processes which result in a medication error. $^{43}$ Two studies reported medication classes cited in claims which included steroid preparations, antibiotics, anticoagulants, antidepressants and antipsychotics. ${ }^{33} 42$ One study reviewed claims resulting from adverse drug events and found that $27 \%$ of primary care adverse drug events were preventable. ${ }^{42}$

\section{Malpractice claims outcomes and compensation awarded}

Seven studies reported the proportion of malpractice claims which were subsequently found to be as a result of negligent care. In one large US study which examined over 27000 resolved family practitioner claims (1985-2008), only $31.9 \%$ resulted in payment. ${ }^{25}$ This concurs with another study which focused on primary care claims (1985-2000) where the rate of paid claims was $28 \% .{ }^{38}$ A smaller US study (4975 family practitioner claims, 1991-2005) reported that approximately $20 \%$ of all claims were settled. ${ }^{17}$ An earlier review in a single US state (1977-1989) reported that $38.7 \%$ of all family/GP claims resulted in payment. ${ }^{30}$ A French study focusing on paediatric claims only ( $16 \%$ involved GPs) reported that $72 \%$ of these claims were paid (either through settlement or at trial). ${ }^{29}$ In 2006, a US review of 226 primary care malpractice claims, which aimed to identify the proportion of claims which resulted from an error and whether this correlated with compensation being awarded, found an error evident in $60 \%$ of claims, of which $73 \%$ were paid. Of a total of $40 \%$ of claims without evidence of error, $29 \%$ were paid. ${ }^{44}$ One US study reported that the mean time to resolution of a total of 2032 family practice malpractice claims was 20.6 months. ${ }^{31}$ In the UK, almost half of the malpractice claims are either discontinued or successfully defended. ${ }^{45}$

The compensation awarded to claimants varied across studies. In the USA, a review of almost 5000 family practice malpractice claims reported mean payments of $\$ 253739.69$ and median payments of $\$ 119389.20 .^{17}$ Diabetes-related indemnity payments for family practitioners ranked second overall in terms of total diabetes indemnity paid totalling $\$ 8316610.00$ for the period $1985-1996 .^{28}$ In Australia, awards of greater than 
$\$ 250000$ were awarded to $15 \%$ of total paid claims. ${ }^{34} \mathrm{~A}$ UK report published in 2011 indicated that compensation awards for GP malpractice claims were rising and that 13 claims were awarded compensation in excess of $£ 1$ million. ${ }^{32}$

\section{DISCUSSION}

\section{Summary of findings}

In the USA, the annual prevalence of malpractice claims against family practitioners appears to have remained relatively stable over the past two decades. When compared with other specialties, family practice is consistently ranked in the top five most sued specialties on US medical indemnity databases. ${ }^{25-28} 30$ This review also indicates that, in the UK and Australia, malpractice claims against GPs are rising. Importantly, the majority of malpractice claims are successfully defended with approximately one-third of US and one-half of UK GP claims resulting in payment to the claimant.

Diagnostic error accounts for the majority of malpractice claims in primary care and the commonest cited missed or delayed diagnoses, for adults, are cancer and myocardial infarction and for children, meningitis. While we acknowledge the limitations of malpractice claims as a proxy for adverse events, it is interesting to note that this finding is congruent with the findings of a review of error in primary care. ${ }^{2}$ The need to focus on diagnosis while developing quality frameworks has recently been highlighted. ${ }^{46}$ Diagnostic error may result as a result of faulty clinical reasoning, misinterpretation of diagnostic tests or be related to or exacerbated by system failures and is often multifactorial. ${ }^{47}$ When we examine in more detail the cognitive processes underlying faulty clinical decision-making, shortcuts in reasoning (heuristics) emerges as an important entity. ${ }^{48} \mathrm{~A}$ recent systematic review which focused on common misdiagnoses in primary care suggested that GPs misattributing presenting symptoms and signs to an obvious or readily available diagnosis may be a key issue. ${ }^{49}$ This process is known as availability heuristics. Estimating the likelihood of a diagnosis with ease of recall is more convenient and often appropriate as familiar diagnoses tend to be those commonly encountered but can lead to error when significant disease is the underlying reason for the encounter. Another issue is that of 'anchoring heuristics', which occurs when doctors tend to maintain initial impressions once they are solidly formed. An existing diagnostic label can reduce the clinician's ability to restructure the diagnostic problem and look for an alternative explanation. In primary care where there is a lower prevalence of serious disease, a doctor's ability to formulate an appropriate differential diagnosis list, gather information to test these diagnostic hypotheses and then accept or reject diagnoses based on this appears to be of key importance. ${ }^{50}$ Medical schools, general practice training programmes and continuing professional development facilitators all have roles to play in ensuring that curricula focuses trainees and practitioners on understanding the nature and psychology of diagnostic error.

Medication error represents the second commonest cause of malpractice claims in this review. A recent UK qualitative study which interviewed 34 prescribers regarding 70 medication errors found that errors were often multifactorial with prescriber, patient and system factors all being contributors. ${ }^{51}$ For the prescriber, the areas highlighted included their therapeutic training, drug knowledge and experience, knowledge of the patient, perception of risk and emotional health. Many of those interviewed felt that their undergraduate prescribing training was inadequate. From a patient perspective, the complexity of the presentation and patient characteristics such as language barriers were highlighted as important factors. From a systems perspective, poor communication, high workload and time pressures were all felt to contribute to medication error. Strategies to reduce medication error therefore should focus on the clinician, patient and system factors.

For doctors, facing a malpractice claim can have serious implications. One clinical implication is the subsequent practice of defensive medicine (medical practice based on fear of litigation rather than patients' best interests), which can result in increased diagnostic testing, increased referral rates, prescription of unnecessary medication and avoiding treating certain conditions or performing certain procedures. ${ }^{52} 53$ This practice can improve patient care but must be balanced with the potential negative consequences both for patients, in terms of undergoing unnecessary investigations, and for the health service, in terms of increased healthcare expenditure. Doctors facing litigation proceedings have also been shown to experience high levels of psychological distress, with one study reporting over one-third considering leaving medicine or retiring early as a result. $^{54}$

\section{Strengths and limitations of this study}

This review is timely considering the increasing interest in focusing on primary care as a way of improving patient safety. There are, however, several limitations. First, it is difficult to generalise results across countries. In the USA, the term 'primary care' often includes internal medicine, general paediatrics and family practice, while in the UK the term is more specific to general practice. Second, while every attempt has been made to be systematic in undertaking this review, the nature of this topic means that many publications appear in the grey literature, making it difficult to be certain that all studies of interest have been captured. Third, as previously outlined, there are well-recognised limitations to using malpractice claims data as a proxy for the totality of adverse events in clinical practice. Finally, this review was limited to publications published in English only and the majority of included studies were from the USA, the UK and Australia, making it 
difficult to draw country-specific conclusions for other countries such as Canada and France.

\section{CONCLUSION}

The increasing recognition of primary care as a setting for adverse events places the development of fit-for-purpose educational strategies and risk management systems as a priority for those interested in promoting patient safety. This review offers insights into the epidemiology of malpractice claims in this setting and highlights areas that could be prioritised both for future research and in the development of risk management systems.

Acknowledgements The authors would like to thank Dr Paul Nisselle and the Medical Protection Society, UK, Anupam B Jena, MD, PhD, Assistant Professor of Health Care Policy and Medicine, Harvard Medical School, Boston, USA and Dr Gordon Wallace and the Canadian Medical Protective Association (CMPA), Canada for providing additional data for this article.

Contributors EW participated in protocol development, literature searching, data extraction, data analysis and manuscript preparation. JL participated in protocol development, literature searching, data extraction and manuscript preparation, SMS participated in protocol development, data analysis and manuscript preparation, TF participated in protocol development, data analysis and manuscript preparation. All authors have read and approved the final manuscript.

Funding This work is supported by the Health Research Board (HRB) of Ireland through the HRB Centre for Primary Care Research under Grant HRC/ 2007/1.

\section{Competing interests None.}

Ethics approval Systematic review.

Provenance and peer review Not commissioned; externally peer reviewed.

Data sharing statement Unpublished data from the Medical Protection Society, UK are available from Dr Paul Nisselle, Senior Consultant, Educational Services, MPS. paul.nisselle@mps.org.uk. Unpublished data from the Canadian Medical Protective Association (CMPA) are available from Dr Gordan Wallace, Director of Education, CMPA. gwallace@cmpa.org. Additional data for Jena, 2011 are available from Professor Jena, Department of Healthcare Policy, Harvard. jena@hcp.med.harvard.edu.

\section{REFERENCES}

1. Bates DW, Gawande AA. Improving safety with information technology. N Engl J Med 2003;348:2526-34.

2. Sandars J, Esmail A. The frequency and nature of medical error in primary care: understanding the diversity across studies. Fam Pract 2003;20:231-6.

3. Elder NC, Dovey SM. Classification of medical errors and preventable adverse events in primary care: a synthesis of the literature. J Fam Pract 2002;51:927-32.

4. Jacobs S, O'Beirne M, Derfiingher LP, et al. Errors and adverse events in family medicine: developing and validating a Canadian taxonomy of errors. Can Fam Physician 2007;53:271-6, 0.

5. Thomas EJ, Petersen LA. Measuring errors and adverse events in health care. J Gen Intern Med 2003;18:61-7.

6. Vincent C, Davy C, Esmail A, et al. Learning from litigation. The role of claims analysis in patient safety. J Eval Clin Pract 2006;12:665-74.

7. Vincent C, Davy C, Esmail A, et al. Learning from litigation: an analysis of claims for clinical negligence. Manchester: University of Manchester, 2004.

8. Hurwitz B. Learning from primary care malpractice: past, present and future. Qual Saf Health Care 2004:13:90-1.

9. Cheney FW. The American Society of Anesthesiologists closed claims project: the beginning. Anesthesiology 2010;113:957-60.
10. Rogers SO Jr, Gawande AA, Kwaan M, et al. Analysis of surgical errors in closed malpractice claims at 4 liability insurers. Surgery 2006;140:25-33.

11. Raine JE. An analysis of successful litigation claims in children in England. Arch Dis Child 2011;96:838-40.

12. Lippman $\mathrm{H}$, Davenport J. Sued for misdiagnosis? It could happen to you. J Fam Pract 2010;59:498-508.

13. Zuccotti G, Sato L. Malpractice risk in ambulatory settings: an increasing and underrecognized problem. JAMA 2011;305:2464-5.

14. Moher D, Liberati A, Tetzlaff J, et al. Preferred reporting items for systematic reviews and meta-analyses: the PRISMA statement. BMJ 2009;339:b2535.

15. Donaldson M, Yordy K, Lohr KN, et al, eds. Primary care: America's health in a new era. Washington, DC: National Academy Press, 1996.

16. Popay J, Roberts H, Sowden A, et al. Guidance on the conduct of narrative synthesis in systematic reviews. Lancaster: Institute of Health Research, ESRC Methods Programme, 2006.

17. Jena $A B$, Seabury $S$, Lakdawalla $D$, et al. Malpractice risk according to physician specialty. N Engl J Med 2011;365:629-36.

18. Virapongse A, Bates DW, Shi P, et al. Electronic health records and malpractice claims in office practice. Arch Intern Med 2008;168:2362-7.

19. Zuckerman S. Medical malpractice: claims, legal costs, and the practice of defensive medicine. Health Aff (Millwood) 1984;3:128-33.

20. Fielding SL. Changing medical practice and medical malpractice claims. Soc Probl 1995;42:38-55.

21. Medical Protection Society. More than two thirds of doctors practice defensively to avoid complaints and claims. Press release 2011.

22. Nash LM, Kelly PJ, Daly MG, et al. Australian doctors' involvement in medicolegal matters: a cross-sectional self-report study. Med J Aust 2009;191:436-40.

23. Kane C. Policy research perspectives-medical liability claim frequency: a 2007-2008 snapshot of physicians. Chicago: American Medical Association, 2010.

24. Najaf-Zadeh A, Dubos F, Pruvost I, et al. Epidemiology and aetiology of paediatric malpractice claims in France. Arch Dis Child 2011;96:127-30.

25. Flannery FT, Parikh PD, Oetgen WJ. Characteristics of medical professional liability claims in patients treated by family medicine physicians. J Am Board Fam Med 2010;23:753-61.

26. Studdert DM, Mello MM, Gawande AA, et al. Claims, errors, and compensation payments in medical malpractice litigation. $N$ Engl J Med 2006;354:2024-33.

27. Troxel D. Do health system errors cause medical malpractice claims. Napa: The Doctors Company, 2008.

28. Meredith V, Cook CB, Penman A. Use of the Physician Insurers Association of America database as a surveillance tool for diabetes-related malpractice claims in the U.S. Diabetes Care 1998;21:1096-100.

29. Najaf-Zadeh A, Dubos F, Aurel M, et al. Epidemiology of malpractice lawsuits in paediatrics. Acta Paediatr 2008;97:1486-91.

30. Kravitz RL, Rolph JE, Petersen L. Omission-related malpractice claims and the limits of defensive medicine. Med Care Res Rev 1997:54:456-71.

31. Seabury SA, Chandra A, Lakdawalla DN, et al. On average, physicians spend nearly 11 percent of their 40-year careers with an open, unresolved malpractice claim. Health Aff (Millwood) 2013;32:111-19.

32. Medical Defence Union (MDU). 'GP claims increase by $20 \%$ '. Press release. 2011

33. Silk N. An analysis of 1000 consecutive general practice negligence claims. Medical Protection Society (MPS), 2000.

34. Australian Institute of Health and Welfare. Public and Private sector medical indemnity claims in Australia. http://www.aihw.gov.au/ search/?q=medical+indemnity+claims (accessed 13 Dec 2012).

35. Gandhi TK, Kachalia A, Thomas EJ, et al. Missed and delayed diagnoses in the ambulatory setting: a study of closed malpractice claims. Ann Intern Med 2006;145:488-96.

36. Canadian Medical Protective Association (CMPA). Critical incident groupings,family, practitioner settlement cases, CMPA 2005-2009. Courtesy of the Research Department, Canadian Medical Protective Association.

37. Fenn P, Gray A, Rivero-Arias O, et al. The epidemiology of error: an analysis of databases of clinical negligence litigation. University of Manchester, Manchester, 2004.

38. Phillips RL Jr, Bartholomew LA, Dovey SM, et al. Learning from malpractice claims about negligent, adverse events in primary care in the United States. Qual Saf Health Care 2004;13:121-6.

39. Esmail A, Neale G, Elstein M, et al. Case studies in litigation: claims reviews in four specialties. University of Manchester, Manchester, 2004 
40. Medical Protection Society (MPS). The GP compass: navigating your way to safer practice. London: MPS, 2011.

41. Nisselle $\mathrm{P}$, Dinwoodle $\mathrm{M}$, Jordache $\mathrm{S}$. Learning from litigation. Meningitis and septicaemia in children. Medical Protection Society, 2012. (Unpublished personal communication).

42. Rothschild JM, Federico FA, Gandhi TK, et al. Analysis of medication-related malpractice claims: causes, preventability, and costs. Arch Intern Med 2002;162:2414-20.

43. Medical Protection Society (MPS). Medication claims review. Courtesy of the Risk Management department of the MPS. 2012.

44. Studdert DM, Mello MM. When tort resolutions are wrong: predictors of discordant outcomes in medical malpractice litigation. $J$ Legal Stud 2007;36:S47-78.

45. Mackenzie P. Learning from clinical claims in primary care. Medical Protection Society (MPS) Casebook. 2011 September 2011:7-9.

46. Graber ML, Wachter RM, Cassel CK. Bringing diagnosis into the quality and safety equations. JAMA 2012;308:1211-12.

47. Graber ML, Franklin N, Gordon R. Diagnostic error in internal medicine. Arch Intern Med 2005;165:1493-9.
48. Redelmeier DA. Improving patient care. The cognitive psychology of missed diagnoses. Ann Intern Med 2005;142:115-20.

49. Kostopoulou O, Delaney BC, Munro CW. Diagnostic difficulty and error in primary care-a systematic review. Fam Pract 2008;25:400-13.

50. Heneghan C, Glasziou P, Thompson M, et al. Diagnostic strategies used in primary care. BMJ 2009;338:b946.

51. Avery T, Barber N, Ghaleb M, et al. Investigating the prevalence and causes of prescribing errors in general practice: Report for the General Medical Council (GMC); May 2012.

52. Nash L, Walton M, Daly M, et al. GPs' concerns about medicolegal issues-how it affects their practice. Aust Fam Physician 2009;38:66-70.

53. Kessler DP, Summerton N, Graham JR. Effects of the medical liability system in Australia, the UK, and the USA. Lancet 2006;368:240-6.

54. Nash LM, Walton MM, Daly MG, et al. Perceived practice change in Australian doctors as a result of medicolegal concerns. Med $J$ Aust 2010;193:579-83. 